\title{
Risk of Second Primary Female Genital Malignancies in Women with Breast Cancer: a SEER Analysis
}

\author{
Zhiyu $\mathrm{Li}^{1} \cdot \mathrm{Qi} \mathrm{Wu}{ }^{1} \cdot$ Junlong Song ${ }^{1} \cdot$ Yimin Zhang $^{1} \cdot$ Shan $\mathrm{Zhu}^{1} \cdot$ Shengrong Sun ${ }^{1}$ (D)
}

Received: 5 January 2018 / Accepted: 5 March 2018 /Published online: 19 March 2018

(C) The Author(s) 2018

\begin{abstract}
Breast cancer survivors are at an increased risk of second primary cancers, and the risk factors for the latter may have clinical significance. The aims of our study were to evaluate the incidences and risk factors of second primary female genital cancers (corpus uteri, cervix uteri plus ovary) in a large cohort of breast cancer survivors. Using the Surveillance, Epidemiology, and End Results (SEER) database, we examined the standardized incidence ratio (SIR) and risk factors for second primary female genital cancers observed between 2000 and 2014. Breast cancer survivors had increased SIRs for second corpus uteri cancers and second ovarian cancers and a decreased SIR for second cervical cancers (SIR 1.17, 1.12, and 0.64, respectively). Risk factors of second corpus uteri cancers were the age at first cancer diagnosis, race (black vs. white, aHR $=1.14295 \%$ CI 1.005-1.298), and progesterone receptor $(\mathrm{PR})$ status ( $\mathrm{PR}+\mathrm{vs} . \mathrm{PR}-, \mathrm{aHR}=1.13195 \% \mathrm{CI} 1.004-1.273$ ). In addition, the risk of second ovarian cancer was positively associated with age while inversely associated with race (black vs. white, aHR $=0.69195 \%$ CI $0.555-$ 0.859 ) and estrogen receptor (ER) status (ER+ vs. ER-, aHR $=0.65595 \%$ CI 0.544-0.788). Age, race, and hormone receptor status are risk factors of developing second female genital cancers among breast cancer survivors. Older age, black race, and a $\mathrm{PR}+$ status in survivors are associated with a higher risk of second corpus uteri cancers. Additionally, older age and an ER-status should increase vigilance for potential second ovarian cancers.
\end{abstract}

Keywords Breast cancer $\cdot$ Second primary female genital cancer $\cdot$ SEER $\cdot$ Risk factor

\section{Introduction}

According to statistics regarding cancer incidence and mortality, breast cancer is the most common malignancy diagnosed in females, accounting for nearly one in three cancers [1]. Breast cancer is also the second leading cause of cancerrelated death after lung cancer among women [2]. With the development of the early screening, detection, and systemic treatment of breast cancer, significant improvements in breast cancer survival outcomes have been made. Thus, women with

Zhiyu Li and Qi Wu contributed equally to this work.

Electronic supplementary material The online version of this article (https://doi.org/10.1007/s12672-018-0330-0) contains supplementary material, which is available to authorized users.

Shengrong Sun sun137@sina.com

1 Department of Breast and Thyroid Surgery, Renmin Hospital of Wuhan University, 238 Ziyang Road, Wuhan 430060, Hubei Province, People's Republic of China breast cancer can achieve prolonged survival times and better life expectancies. However, a higher risk of developing a second primary female genital cancer among breast cancer survivors may translate into an important health problem in their lifetimes [3]. Within 10 years after the initial diagnosis, approximately $10 \%$ of breast cancer patients develop a subsequent primary cancer, including second primary endometrial cancer and second primary ovarian cancer [4].

Previous studies have suggested a consensus in the increased risk of second primary female genital cancers among breast cancer survivors. A large cohort study reported that women with breast cancer had a $30 \%$ excess risk for second primary cancers, particularly for endometrial cancer and ovarian cancer [5]. The problem of second primary female genital cancers among breast cancer survivors may be related to treatment side effects or to etiological associations for multiple cancers. With the growing interest in identifying possible relationships between second female genital malignancies and first cancers, studies have focused on multiple factors, such as lifestyle, environment, treatment side effects, and hormonal and/or genetic factors. A European study reported that risk 
factors of second female genital malignancies included the body mass index and smoking status of breast cancer patients [5]. Moreover, estrogen receptor (ER)-positive breast cancer patients treated with tamoxifen have an increased risk of subsequent endometrial cancer [6, 7]. However, one study has shown that patients with breast cancer have a higher risk of subsequent endometrial cancer regardless of ER or progesterone receptor (PR) status [8].

The aims of our study were to systemically evaluate the incidence of second primary female genital cancers in a large cohort of breast cancer patients and to identify risk factors for second primary corpus uteri cancer and ovarian cancer. Using the Surveillance, Epidemiology, and End Results (SEER) database, we calculated the standardized incidence ratio (SIR) for second primary cancers after breast cancer diagnosed between 2000 and 2014. Meanwhile, we used multivariable analysis to examine the risk factors for the development of a second primary female genital cancer after breast cancer.

\section{Materials and Methods}

\section{Data Source and Study Design}

The SEER program of the National Cancer Institute collects information on cancer incidence, patient survival, and patient characteristics from several geographically defined regions in the USA. Data were selected from the SEER 18 registry database from January 1, 2000, to December 31, 2014. The registries included San Francisco-Oakland SMSA, Connecticut, Detroit (Metropolitan), Hawaii, Iowa, New Mexico, Seattle (Puget Sound), Utah, Atlanta (Puget Sound), San JoseMonterey, Los Angeles, Rural Georgia, California excluding SF/SJM/LA, Kentucky, Louisiana, New Jersey, and Greater Georgia. The International Classification of Diseases for Oncology, 3rd edition (ICD-O-3) histopathology codes were used to analyze the cases of malignancy.

From this database, we collected data for women with breast cancer only and breast cancer survivors with multiple cancers who were diagnosed between 2000 and 2014. Second primary cancers that were diagnosed within 6 months of breast cancer diagnosis were excluded as these were likely to be preexisting or synchronous cancers [8]. Cases derived only from death certificates or autopsy were also excluded. Follow-up continued until the date of diagnosis of any second cancer, death from any cause, the date of last known vital status, or the end of the study (December 31, 2014). In the Cox proportional hazards regression model analysis of risk factors for second female genital cancers after breast cancer, none of the follow-up data were excluded.

There were 615,581 women with breast cancer only and 50,681 breast cancer survivors with multiple cancers in this database. A total of 4740 patients developed a second female genital cancer after a primary breast cancer diagnosis, including 3033 women with second corpus uteri cancer, 295 women with cervical cancer, and 1412 with ovarian cancer. Additionally, analyses were conducted based on the characteristics of the first breast cancer, which included the year of breast cancer diagnosis (2000-2004, 2005-2009, and 2010 2014), age at breast cancer diagnosis (age under 40, 40-49, $50-59,60-69$, and $70+$ years), latency period $(6-11,12-59$, 60-119, and 120+ months), race (white, black, American Indian/Alaskan Native, Asian, or Pacific islander), subtype $(\mathrm{ER}+\mathrm{PR}+, \mathrm{ER}+\mathrm{PR}-, \mathrm{ER}-\mathrm{PR}+, \mathrm{ER}-\mathrm{PR}-)$, and menopausal status (premenopausal, perimenopausal, and postmenopausal) [9].

\section{Statistical Analysis}

\section{Estimation of Standardized Incidence Ratio}

To compare the relative risk with the general population, we used the SEER*Stat Multiple primary-standardized incidence ratios (MP-SIR) tool (version 8.3.4) to calculate the SIRs by dividing the observed numbers of second primary cancers by the expected numbers of second primary cancers based on the rates of the general population, along with the $95 \%$ confidence interval $(95 \% \mathrm{CI})$. CIs and $P$ values were at 0.05 significance alpha levels and were two-sided based on Poisson exact methods. To avoid statistically unstable estimates, the SIRs and CIs of the 0-20 age group were not presented where the number of observed cases was zero [10].

\section{Risk Factors Analysis}

The characteristics of the women with breast cancer only and those with second primary female genital cancer were compared with chi-square tests. We used crude semi-parametric Cox proportional hazards regressions to evaluate the hazards ratios (HRs) and corresponding 95\% CIs and to show the risk factors for the development of a second primary female genital cancer after breast cancer. The latency period was started at the first breast cancer diagnosis and censored at the second cancer diagnosis. All statistical analyses and charts were generated using SPSS 19.0 (IBM Corporation, Armonk, NY, USA) and GraphPad Prism 6.07. Significance levels were set at $p$ value $<0.05$. All tests were two-sided.

\section{Results}

\section{SIRs for Second Female Genital Cancers Among Breast Cancer Survivors}

Table 1 shows the SIRs for second primary cervical cancer and second primary corpus uteri cancer among breast cancer survivors. There were 295 cervical cancers and 3033 
Table 1 Standardized incidence ratios for second cervical cancer and corpus uteri cancer risk in breast cancer patients by characteristic

\begin{tabular}{|c|c|c|c|c|}
\hline \multirow[t]{2}{*}{ Characteristics } & \multicolumn{2}{|c|}{ Cervix uteri } & \multicolumn{2}{|c|}{ Corpus uteri } \\
\hline & $O$ & $\operatorname{SIR}(95 \% \mathrm{CI})$ & $O$ & $\operatorname{SIR}(95 \% \mathrm{CI})$ \\
\hline \multicolumn{5}{|c|}{ Calendar year of breast cancer diagnosis } \\
\hline $2000-2004$ & 33 & $0.55^{*}(0.38,0.78)$ & 352 & $\mathbf{1 . 3 7} *(1.23,1.52)$ \\
\hline 2005-2009 & 114 & $0.69 *(0.57,0.83)$ & 1073 & $\mathbf{1 . 2 6} *(1.19,1.34)$ \\
\hline 2010-2014 & 148 & $0.63 *(0.54,0.74)$ & 1608 & $\mathbf{1 . 0 8}^{*}(1.03,1.13)$ \\
\hline \multicolumn{5}{|l|}{ Age at breast cancer diagnosis, years } \\
\hline Age under 40 & 4 & $0.33 *(0.09,0.84)$ & 9 & $1.31(0.60,2.48)$ \\
\hline $40-49$ & 36 & $0.53 *(0.37,0.73)$ & 150 & $\mathbf{1 . 5 5}^{*}(1.32,1.82)$ \\
\hline $50-59$ & 79 & $0.67 *(0.53,0.83)$ & 677 & $\mathbf{1 . 2 1} *(1.12,1.30)$ \\
\hline $60-69$ & 66 & $0.53 *(0.41,0.68)$ & 916 & $0.97(0.91,1.03)$ \\
\hline $70+$ & 110 & $0.81 *(0.67,0.98)$ & 1281 & $\mathbf{1 . 3 0} *(1.23,1.37)$ \\
\hline \multicolumn{5}{|l|}{ Latency period, months } \\
\hline $6-11$ & 27 & $0.66 *(0.44,0.97)$ & 202 & $1.02(0.89,1.17)$ \\
\hline $12-59$ & 140 & $0.59 *(0.49,0.69)$ & 1423 & $\mathbf{1 . 1 3} *(1.07,1.19)$ \\
\hline $60-119$ & 106 & $0.75 *(0.61,0.90)$ & 1074 & $\mathbf{1 . 2 2} *(1.15,1.30)$ \\
\hline $120+$ & 22 & $0.60 *(0.38,0.91)$ & 334 & $1.27^{*}(1.14,1.42)$ \\
\hline \multicolumn{5}{|l|}{ Race } \\
\hline White & 228 & $0.64 *(0.56,0.72)$ & 2507 & $\mathbf{1 . 1 2} *(1.08,1.16)$ \\
\hline Black & 43 & $0.69 *(0.50,0.93)$ & 288 & $\mathbf{1 . 3 5}^{*}(1.20,1.51)$ \\
\hline American Indian/Alaskan Native & 1 & $0.56(0.01,3.12)$ & 7 & $1.05(0.42,2.17)$ \\
\hline Asian or Pacific Islander & 22 & $0.64 *(0.40,0.98)$ & 226 & $\mathbf{1 . 8 2} *(1.59,2.08)$ \\
\hline \multicolumn{5}{|l|}{ Menopausal status $^{1}$} \\
\hline Premenopausal ( $\leq 45$ years) & 24 & $0.54^{*}(0.35,0.81)$ & 52 & $1.27(0.95,1.67)$ \\
\hline Perimenopausal (46-55 years) & 60 & $0.57 *(0.43,0.73)$ & 452 & $1.37^{*}(1.24,1.50)$ \\
\hline Postmenopausal (56+ years) & 211 & $0.68^{*}(0.59,0.78)$ & 2529 & $\mathbf{1 . 1 4} *(1.09,1.18)$ \\
\hline \multicolumn{5}{|l|}{ Subtype } \\
\hline $\mathrm{ER}+\mathrm{PR}+$ & 169 & $0.63 *(0.64,0.73)$ & 1818 & $\mathbf{1 . 1 7 *}(1.11,1.22)$ \\
\hline $\mathrm{ER}+\mathrm{PR}-$ & 25 & $0.52 *(0.34,0.77)$ & 305 & $1.04(0.93,1.17)$ \\
\hline $\mathrm{ER}-\mathrm{PR}+$ & 4 & $0.71(0.19,1.82)$ & 38 & $\mathbf{1 . 4 3}^{*}(1.01,1.96)$ \\
\hline $\mathrm{ER}-\mathrm{PR}-$ & 48 & $0.62 *(0.46,0.83)$ & 439 & $\mathbf{1 . 1 3}^{*}(1.03,1.24)$ \\
\hline
\end{tabular}

The bold values indicate the SIR (risk) for developing a second primary cancer was significantly increased The italic values indicate the SIR (risk) for developing a second primary cancer was significantly decreased $O$ observed numbers, SIR standardized incidence ratio, $H R$ hormone receptor, $E R$ estrogen receptor, $P R$ progesterone receptor

$* P<0.05$; confidence intervals are $95 \%$

${ }^{1}$ Women were considered perimenopausal if their age is in between 46 and 55 years, and the menopausal status is unknown

endometrial cancers after first primary breast cancer (Supplementary Table 1). The SIR for cervical cancer was decreased with statistical significance for patients with first breast cancer, while the SIR for corpus uteri cancer increased for patients with first breast cancer (SIR, 0.64; 95\% CI, $0.57-$ 0.72; SIR, 1.17; 95\% CI, 1.13-1.21, respectively). Decreased SIRs for cervical cancer patients were observed for all years of breast cancer diagnosis, all ages at breast cancer diagnosis, all latency periods, and all menopausal statuses after breast cancer diagnosis. The SIRs for the ER+ and ER-PR- subtypes were both decreased in patients with cervical cancer. In addition, the increased SIRs for corpus uteri cancer patients were observed in all years of breast cancer diagnosis but declined for more recent time periods (2000-2004 SIR, 1.37; 2005-2009 SIR, 1.26; 2010-2014 SIR, 1.08). The SIRs for all latency periods except the first 6-11 months after breast cancer diagnosis were elevated and increased with the time period (12-59 SIR, 1.13; 60-119 SIR, 1.22; 120+ SIR, 1.27). The SIRs for ER+PR+ and ER- breast cancer were all elevated in patients with corpus uteri cancer.

Table 2 shows the SIRs for patients with second primary ovarian cancer after first breast cancer (SIR, 1.12; 95\% CI, 
Table 2 Standardized incidence ratios for second ovarian cancer risk in breast cancer patients by characteristic

\begin{tabular}{|c|c|c|}
\hline Characteristics & $O$ & $\operatorname{SIR}(95 \% \mathrm{CI})$ \\
\hline \multicolumn{3}{|c|}{ Calendar year of breast cancer diagnosis } \\
\hline $2000-2004$ & 195 & $\mathbf{1 . 2 9} *(1.12-1.49)$ \\
\hline 2005-2009 & 528 & $\mathbf{1 . 1 7} *(1.07-1.27)$ \\
\hline $2010-2014$ & 689 & $1.04(0.97-1.13)$ \\
\hline \multicolumn{3}{|l|}{ Age at breast cancer diagnosis, years } \\
\hline Age under 40 & 24 & $\mathbf{6 . 0 0} *(3.84-8.93)$ \\
\hline $40-49$ & 148 & $2.43 *(2.06-2.86)$ \\
\hline $50-59$ & 325 & $\mathbf{1 . 4 6}^{*}(1.31-1.63)$ \\
\hline $60-69$ & 364 & $1.03(0.93-1.14)$ \\
\hline $70+$ & 551 & $0.89 *(0.81-0.96)$ \\
\hline \multicolumn{3}{|l|}{ Latency period, months } \\
\hline $6-11$ & 113 & $1.14(0.94-1.36)$ \\
\hline $12-59$ & 686 & $\mathbf{1 . 1 0} *(1.02-1.19)$ \\
\hline $60-119$ & 485 & 1.16* (1.06-1.27) \\
\hline $120+$ & 128 & $1.07(0.89-1.27)$ \\
\hline \multicolumn{3}{|l|}{ Race } \\
\hline White & 1213 & $\mathbf{1 . 0 9} *(1.03,1.15)$ \\
\hline Black & 99 & $1.18(0.96,1.43)$ \\
\hline American Indian/Alaskan Native & 5 & $1.67(0.54,3.90)$ \\
\hline Asian or Pacific Islander & 95 & 1.66* $(1.35,2.03)$ \\
\hline \multicolumn{3}{|l|}{ Menopausal status ${ }^{1}$} \\
\hline $\begin{array}{l}\text { Premenopausal } \\
\text { ( } \leq 45 \text { years) }\end{array}$ & 97 & $3.67 *(2.97,4.47)$ \\
\hline $\begin{array}{l}\text { Perimenopausal } \\
\text { (46-55 years) }\end{array}$ & 256 & $\mathbf{1 . 6 3}^{*}(1.44,1.84)$ \\
\hline $\begin{array}{l}\text { Postmenopausal } \\
(56+\text { years }) \\
\text { Subtype }\end{array}$ & 1059 & $0.98(0.92,1.04)$ \\
\hline $\mathrm{ER}+\mathrm{PR}+$ & 695 & $0.92 *(0.85-0.99)$ \\
\hline $\mathrm{ER}+\mathrm{PR}-$ & 151 & $1.06(0.89-1.24)$ \\
\hline $\mathrm{ER}-\mathrm{PR}+$ & 27 & 2.18* $(1.43-3.17)$ \\
\hline $\mathrm{ER}-\mathrm{PR}-$ & 321 & $\mathbf{1 . 8 1} *(1.62-2.02)$ \\
\hline
\end{tabular}

The bold values indicate the SIR (risk) for developing a second primary cancer was significantly increased

The italic values indicate the SIR (risk) for developing a second primary cancer was significantly decreased

$O$ observed numbers, $S I R$ standardized incidence ratio, $H R$ hormone receptor, $E R$ estrogen receptor, $P R$ progesterone receptor

$* P<0.05$; confidence intervals are $95 \%$

${ }^{1}$ Women were considered perimenopausal if their age is in between 46 and 55 years, and the menopausal status is unknown

1.06-1.18). A total of 1412-s primary ovarian cancers were examined and analyzed in our study. The elevated SIRs were observed in groups containing patients under 60 years of age, and the SIRs decreased with increasing age at breast cancer diagnosis (age under $40 \mathrm{SIR}, 6.00 ; 40-49 \mathrm{SIR}, 2.43 ; 50-59$ SIR, 1.46). In the 70+ age group, patients with first breast cancer had a decreased risk of developing second ovarian cancer compared to the general group (SIR, 0.89 ; $95 \%$ CI, $0.81-$ 0.96). Elevated SIRs were also observed in the 12-119month latency periods (12-59 SIR, 1.10; 60-119 SIR, 1.16). Additionally, SIRs for second primary ovarian cancer were significantly increased after ER- breast cancer (ER-PR+ SIR, 2.18; ER-PR- SIR,1.81). In contrast, for the ER+PR+ subtype of breast cancer, there was a decreased risk of developing second ovarian cancer (SIR, 0.92 ; 95\% CI, 0.85-0.99). Meanwhile, premenopausal patients showed higher SIRs than those with other menopausal statuses.

\section{Risk Factors of Developing a Second Female Genital Cancer After Breast Cancer}

The clinical characteristics of the women who developed breast cancer only and those who developed second primary female genital cancer are shown in the supplementary Tables. Women with breast cancer only differed from those who developed second primary corpus uteri cancer in terms of the year of breast cancer diagnosis, age at breast cancer diagnosis, race, and ER and PR status, based on significant differences in chi-square tests (Supplementary Table 1). Women with breast cancer only also differed significantly from those who developed second primary ovarian cancer in terms of the year of breast cancer diagnosis, race, and ER and PR status (Supplementary Table 2). With regard to age at breast cancer diagnosis, we found no statistically significant differences between women with breast cancer only and women with second primary ovarian cancer.

When we considered risk factors for second primary corpus uteri cancer after breast cancer (Table 3), the risk of second primary corpus uteri cancer was positively associated with the age at first cancer $(46-55$ vs. $\leq 45$ years, aHR $=2.343$, $P<0.001 ; 56+$ vs. $\leq 45$ years, aHR $=3.218, P<0.001$ ) (Fig. 1a), race (black vs. white, aHR $=1.142, P=0.042$ ), and PR status (positive vs. negative, aHR $=1.131, P=0.043$ ) (Fig. 1b), while an inverse association was found with the year of first cancer, and ER status showed no association with risk $(P=$ 0.293). Our study also demonstrated that the risk of second primary ovarian cancer was positively associated with the year of first cancer and age at first cancer $(56+$ years vs. $\leq 45$ years, $\mathrm{aHR}=1.453, P<0.001$ ) (Fig. 1c), while an inverse association was found with race (black vs. white, aHR $=0.691, P=0.001$ ) and ER status (positive vs. negative, aHR $=0.655, P<0.001$ ) (Fig. 1d), and PR status showed no association with risk $(P=$ 0.060).

\section{Discussion}

In this study, we found a significantly decreased risk of second cervical cancer in patients with first breast cancer. Viral carcinogenesis is the main risk factor for cervical cancer. 
Table 3 Cox proportional hazards regression model analysis of risk factors for second female genital cancers after breast cancer: adjusted hazard ratio (aHR) and $95 \%$ confidence interval $(95 \% \mathrm{CI})$

\begin{tabular}{|c|c|c|c|c|}
\hline \multirow[t]{2}{*}{ Variables } & \multicolumn{2}{|l|}{ Corpus uteri } & \multicolumn{2}{|l|}{ Ovary } \\
\hline & aHR $(95 \% \mathrm{CI})$ & $P$ value & aHR $(95 \%$ CI) & $P$ value \\
\hline \multicolumn{5}{|c|}{ Calendar year of breast cancer diagnosis } \\
\hline $2000-2004$ & Reference & & Reference & \\
\hline 2005-2009 & $0.769(0.704,0.841)$ & $<0.001$ & $1.321(1.104,1.580)$ & 0.002 \\
\hline $2010-2014$ & $0.711(0.616,0.820)$ & $<0.001$ & $1.840(1.277,2.652)$ & 0.001 \\
\hline \multicolumn{5}{|l|}{ Age at diagnosis } \\
\hline$\leq 45$ years & Reference & & Reference & \\
\hline $46-55$ years & $2.343(1.990,2.758)$ & $<0.001$ & $1.146(0.951,1.382)$ & 0.153 \\
\hline $56+$ years & $3.218(2.764,3.746)$ & $<0.001$ & $1.453(1.231,1.716)$ & $<0.001$ \\
\hline \multicolumn{5}{|l|}{ Race } \\
\hline White & Reference & & Reference & \\
\hline Black & $1.142(1.005,1.298)$ & 0.042 & $0.691(0.555,0.859)$ & 0.001 \\
\hline American Indian/Alaskan Native & $0.558(0.266,1.173)$ & 0.124 & $0.783(0.325,1.886)$ & 0.586 \\
\hline Asian or Pacific Islander & $1.072(0.928,1.239)$ & 0.346 & $0.962(0.776,1.194)$ & 0.727 \\
\hline \multicolumn{5}{|l|}{ ER } \\
\hline Negative & Reference & & Reference & \\
\hline Positive & $0.928(0.808,1.066)$ & 0.293 & $0.655(0.544,0.788)$ & $<0.001$ \\
\hline \multicolumn{5}{|l|}{ PR } \\
\hline Negative & Reference & & Reference & \\
\hline Positive & $1.131(1.004,1.273)$ & 0.043 & $0.848(0.715,1.007)$ & 0.060 \\
\hline
\end{tabular}

* $P$ values calculated by Log-rank testing; bold if statistically significant, $P<0.05$
Moreover, a previous study showed the induction of aromatase expression in cervical carcinomas and opened the possibility that the use of aromatase inhibitors (AIs) for primary breast cancer may be a potential favorable factor in the development of subsequent cervical cancer [11]. Additionally, the cervix is targeted by estrogen through estrogen receptor alpha and beta (ER- $\alpha$ and ER- $\beta$ ). ER- $\alpha$ expression occurs mainly in the normal cervical epithelium but is lost in cervical cancer. However, ER- $\beta$ is expressed in both the normal cervix and cervical cancer. One study has suggested that estrogen may affect ER- $\beta$, which is a suppressor of ER- $\alpha$ in carcinogenesis [12]. Thus, AI therapy for postmenopausal breast cancer patients and ER- $\beta$ expression might be the causes of the decreased risk of second cervical cancer among breast cancer survivors.

Our study showed that the SIR for second primary corpus uteri cancer was significantly increased in patients with first breast cancer regardless of ER and PR status. Previous studies have confirmed an increased risk of second corpus uteri cancer after ER-positive breast cancer in patients with tamoxifen therapy compared to the general population [13, 14]. Interestingly, ER-PR- breast cancer patients who were less likely to receive tamoxifen therapy also had a significantly increased SIR for second corpus uteri cancer, and this result suggests that tamoxifen therapy may not be the only potential reason for second corpus uteri cancer after initial breast cancer. The results of a recent study were consistent with our study, which showed that breast cancer patients with different hormone receptor statuses had increased risks of subsequent corpus uteri cancer [8]. In addition to tamoxifen therapy, shared BRCA1/2 gene mutations may contribute to a higher risk of corpus uteri cancer among breast cancer patients, compared to the general population [15]. Our study suggested a trend in which the SIR of second corpus uteri cancer was declining more in recent years. However, this trend may be merely a reflection of the shorter latency period for breast cancer survivors more recently. On the one hand, Table 1 shows that the risk of second uterine corpus cancer increases with the latency period. On the other hand, a large case-control study found that patients using tamoxifen for less than 2 years failed to show a statistically increased risk of developing uterine corpus cancer [16]. Our study continued until December 31,2014 , and revealed that numerous breast cancer patients diagnosed from 2010 to 2014 may have undergone tamoxifen treatment for less than 2 years, so the effect of tamoxifen on second uterine corpus cancer development among these patients was underestimated.

Our study suggested that survivors had a higher risk of developing second primary ovarian cancer after the first breast cancer than the general population, which was in line with previous studies $[17,18]$. The results further revealed that the young breast cancer survivors had a higher risk of second primary ovarian cancer than young women in the general population, and the peak of this risk was particularly notable 

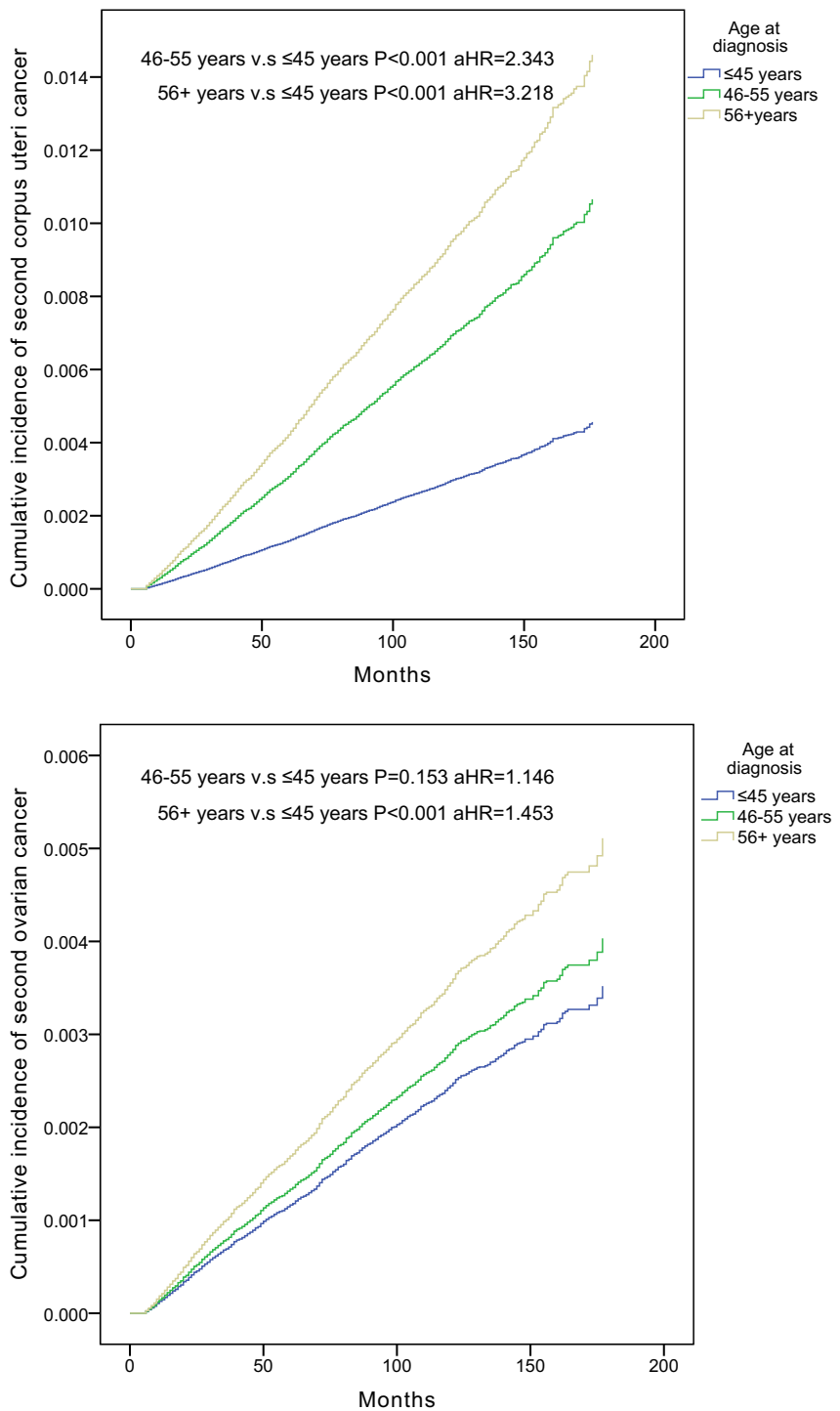

Fig. 1 Cumulative incidence curves of second corpus uteri cancer among breast cancer survivors in different age groups. Cumulative incidence curves of second corpus uteri cancer in PR+ breast cancer survivors compared with PR- survivors. Cumulative incidence curves of second

in the 30-39 age group but lowest in the 70+ age group. This may be associated with a common germline mutation (BRCA1) and similar hormonal exposure. To some extent, BRCA1 mutations expressly cause breast cancer at a young age [19]. In addition, oophorectomy, a treatment for breast cancer, can lead to an incidental finding of early ovarian cancer. The SIRs for second primary ovarian cancer were significantly increased after ER-negative breast cancer. This increase may be related to the common BRCA1 gene for both early-onset ER-negative breast cancer and ovarian cancer [20]. Surprisingly, for both corpus uteri and ovarian sites, women with ER-PR+ breast cancer appeared to have the highest risk. However, progesterone signaling should not be viewed as a risk factor for both uterine corpus and ovarian
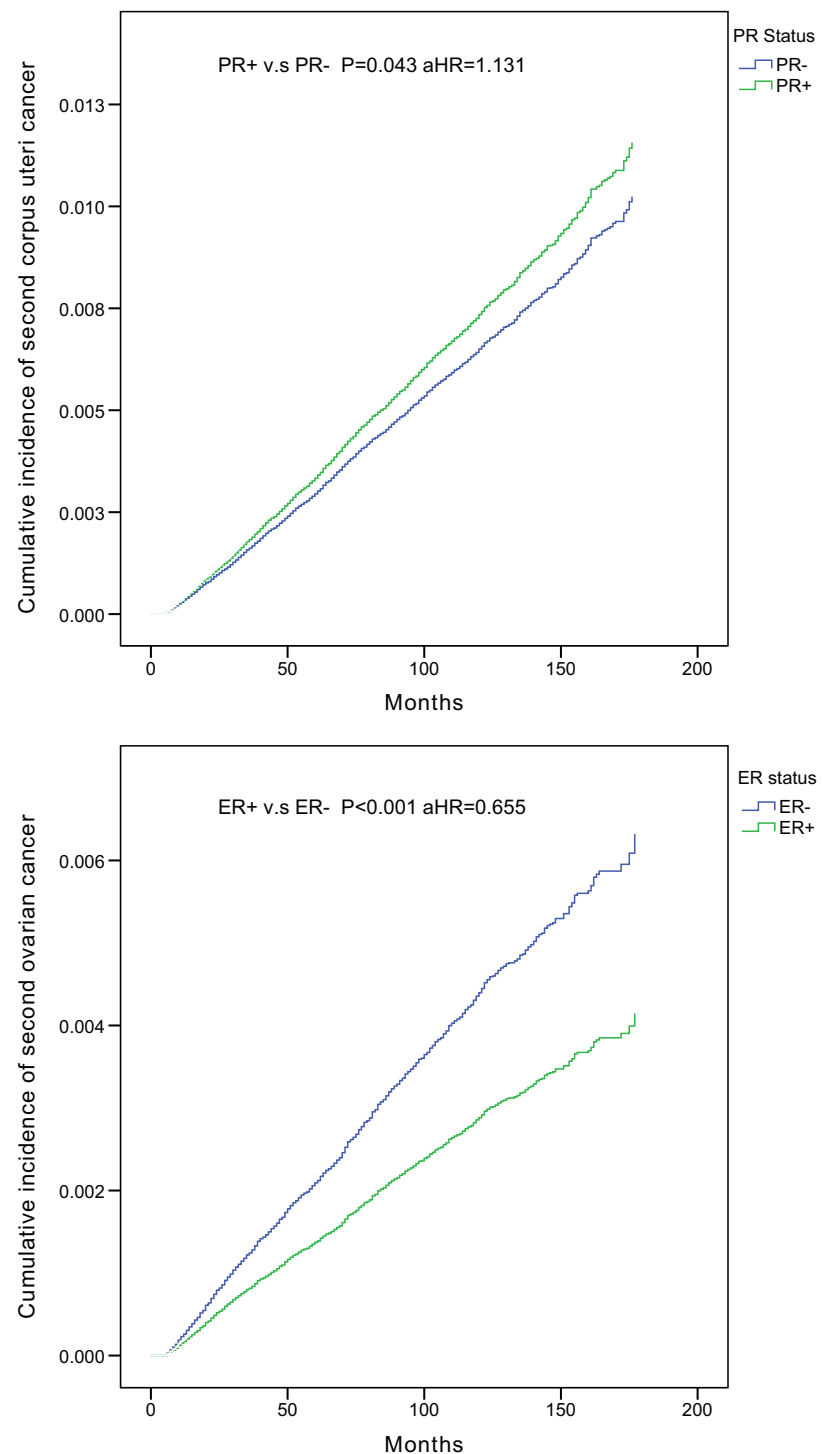

ovarian cancer among breast cancer survivors in different age groups. Cumulative incidence curves of second ovarian cancer in ER+ breast cancer survivors compared with ER- survivors

cancers. Progesterone is a favorable prognostic factor and inhibits cancer cell growth and metastasis development in both uterine corpus cancer and ovarian cancer [21]. ER-PR+ breast cancer is rare because PRs are ER-induced genes and because PR positivity is driven by an active ER. Thus, the expression of ER-PR+ may be induced by other signaling. This alternative signaling may explain how ER-PR+ breast cancers are associated with earlier recurrence times and poorer overall survival rates than $\mathrm{ER}+\mathrm{PR}+$ breast cancers [22]. Patients with ER-PR+ breast cancers still receive tamoxifen therapy and are influenced by the side effects of tamoxifen, but these patients have poorer outcomes than $\mathrm{ER}+\mathrm{PR}+$ patients.

In contrast to previous studies, we had extensive information on cancer risk factors for second female genital cancers, 
including the year of breast cancer diagnosis, age at breast cancer diagnosis, race, and hormone receptor status. For breast cancer survivors, in the development of second primary female genital cancer, older age (45+ years), black race, and $\mathrm{PR}+$ breast cancer tended to be associated with a higher risk of second corpus uteri cancer. Meanwhile, older age (56+ years), white race, and ER- breast cancer needed heightened vigilance for potential second ovarian cancer. Elevated risks were noted in patients who were perimenopausal or postmenopausal, which may indicate an age-related preference in the risk of second primary female genital cancer among breast cancer patients. However, ER+ breast cancer patients had a decreased risk of developing second ovarian cancer compared to ERpatients. This decreased risk may be due to hormone therapy for first breast cancer. Nevertheless, the SEER database does not contain complete treatment information to evaluate the impact of hormone therapy.

Our study had strengths and weaknesses. This study was based on a large, well-established, and standardized population database. However, the heterogeneous population and retrospective analysis of the SEER data were the main limitations. In addition, patients with first primary breast cancer tend to be given more thorough attention than the general population, and a surveillance bias exists for patients with second primary cancer. To address these issues, we analyzed data from a 15-year period and data from 18 registries, making these systemic errors non-differential. Potential pre-existing or synchronous cancers were another concern. Therefore, patients with second primary cancers diagnosed within 6 months of breast cancer diagnosis were excluded from our cohort. Moreover, due to the composition of the dataset, the numbers of patients for second female genital cancers in some race and age groups of breast cancer patients were small. These relevant findings would need further confirmation.

In conclusion, this large population-based study suggests that women with first primary breast cancer have higher risks of developing second primary corpus uteri cancer and second primary ovarian cancer than the general population. In contrast, breast cancer survivors have a decreased risk of developing second primary cervical cancer. These increased and decreased risks of developing second primary cancers suggest associations with breast tumor biology and shared genetic susceptibility. Meanwhile, several risk factors were associated with an increase (age at first cancer, race, PR status) or a decrease (year of first cancer) of second primary corpus uteri cancer and with an increase (year of first cancer, age at first cancer) or a decrease (race, ER status) of second primary ovarian cancer. These findings are useful for health planning, including screening and the development of specific guidelines for both the general population and breast cancer patients. Further work is needed to explore possible reasons for this association and the survival outcomes of these patients.
Funding This work was partially supported by a National Natural Science Foundation of China (NSFC) grant (grant no.: 81471781) and a National major scientific instruments and equipment development projects grant (grant no.: 2012YQ160203) to Dr. Shengrong Sun. This work was also supported by a NSFC grant (grant no.: 81502665) to Yimin Zhang and a Fundamental Research Funds for the Central Universities of China grant to Shan Zhu (grant no.: 2042014kf0189).

\section{Compliance with Ethical Standards}

Conflict of Interest The authors declare that they have no conflict of interest.

Open Access This article is distributed under the terms of the Creative Commons Attribution 4.0 International License (http:// creativecommons.org/licenses/by/4.0/), which permits unrestricted use, distribution, and reproduction in any medium, provided you give appropriate credit to the original author(s) and the source, provide a link to the Creative Commons license, and indicate if changes were made.

\section{References}

1. Nelson HD, Zakher B, Cantor A, Fu R, Griffin J, O'Meara ES, Buist DS, Kerlikowske K, van Ravesteyn NT, Trentham-Dietz A, Mandelblatt JS, Miglioretti DL (2012) Risk factors for breast cancer for women aged 40 to 49 years: a systematic review and metaanalysis. Ann Intern Med 156(9):635-648. https://doi.org/10. 7326/0003-4819-156-9-201205010-00006

2. DeSantis CE, Fedewa SA, Goding Sauer A, Kramer JL, Smith RA, Jemal A (2016) Breast cancer statistics, 2015: convergence of incidence rates between black and white women. CA Cancer J Clin 66(1):31-42. https://doi.org/10.3322/caac.21320

3. Molina-Montes E, Pollan M, Payer T, Molina E, Davila-Arias C, Sanchez MJ (2013) Risk of second primary cancer among women with breast cancer: a population-based study in Granada (Spain). Gynecol Oncol 130(2):340-345. https://doi.org/10.1016/j.ygyno. 2013.04.057

4. Hayat MJ, Howlader N, Reichman ME, Edwards BK (2007) Cancer statistics, trends, and multiple primary cancer analyses from the Surveillance, Epidemiology, and End Results (SEER) program. Oncologist 12(1):20-37. https://doi.org/10.1634/theoncologist.12-1-20

5. Ricceri F, Fasanelli F, Giraudo MT, Sieri S, Tumino R, Mattiello A, Vagliano L, Masala G, Quiros JR, Travier N, Sanchez MJ, Larranaga N, Chirlaque MD, Ardanaz E, Tjonneland A, Olsen A, Overvad K, Chang-Claude J, Kaaks R, Boeing H, Clavel-Chapelon F, Kvaskoff M, Dossus L, Trichopoulou A, Benetou V, Adarakis G, Bueno-de-Mesquita HB, Peeters PH, Sund M, Andersson A, Borgquist S, Butt S, Weiderpass E, Skeie G, Khaw KT, Travis RC, Rinaldi S, Romieu I, Gunter M, Kadi M, Riboli E, Vineis P, Sacerdote C (2015) Risk of second primary malignancies in women with breast cancer: results from the European prospective investigation into cancer and nutrition (EPIC). Int J Cancer 137(4):940 948. https://doi.org/10.1002/ijc.29462

6. Curtis RE, Freedman DM, Sherman ME, Fraumeni JF Jr (2004) Risk of malignant mixed Mullerian tumors after tamoxifen therapy for breast cancer. J Natl Cancer Inst 96(1):70-74

7. Swerdlow AJ, Jones ME, British Tamoxifen Second Cancer Study $G$ (2005) Tamoxifen treatment for breast cancer and risk of endometrial cancer: a case-control study. J Natl Cancer Inst 97(5):375384. https://doi.org/10.1093/jnci/dji057

8. Liu J, Jiang W, Mao K, An Y, Su F, Kim BY, Liu Q, Jacobs LK (2015) Elevated risks of subsequent endometrial cancer 
development among breast cancer survivors with different hormone receptor status: a SEER analysis. Breast Cancer Res Treat 150(2): 439-445. https://doi.org/10.1007/s10549-015-3315-5

9. Mellemkjaer L, Friis S, Olsen JH, Scelo G, Hemminki K, Tracey E, Andersen A, Brewster DH, Pukkala E, McBride ML, Kliewer EV, Tonita JM, Kee-Seng C, Pompe-Kirn V, Martos C, Jonasson JG, Boffetta P, Brennan P (2006) Risk of second cancer among women with breast cancer. Int J Cancer 118(9):2285-2292. https://doi.org/ 10.1002/ijc. 21651

10. Kim C, Bi X, Pan D, Chen Y, Carling T, Ma S, Udelsman R, Zhang $\mathrm{Y}$ (2013) The risk of second cancers after diagnosis of primary thyroid cancer is elevated in thyroid microcarcinomas. Thyroid 23(5):575-582. https://doi.org/10.1089/thy.2011.0406

11. Nair HB, Luthra R, Kirma N, Liu YG, Flowers L, Evans D, Tekmal RR (2005) Induction of aromatase expression in cervical carcinomas: effects of endogenous estrogen on cervical cancer cell proliferation. Cancer Res 65(23):11164-11173. https://doi.org/10.1158/ 0008-5472.CAN-05-1087

12. Lopez-Romero R, Garrido-Guerrero E, Rangel-Lopez A, ManuelApolinar L, Pina-Sanchez P, Lazos-Ochoa M, Mantilla-Morales A, Bandala C, Salcedo M (2013) The cervical malignant cells display a down regulation of ER-alpha but retain the ER-beta expression. Int J Clin Exp Pathol 6(8):1594-1602

13. van Leeuwen FE, Benraadt J, Coebergh JW, Kiemeney LA, Gimbrere CH, Otter R, Schouten LJ, Damhuis RA, Bontenbal M, Diepenhorst FW et al (1994) Risk of endometrial cancer after tamoxifen treatment of breast cancer. Lancet 343(8895):448-452

14. Chen JY, Kuo SJ, Liaw YP, Avital I, Stojadinovic A, Man YG, Mannion C, Wang J, Chou MC, Tsai HD, Chen ST, Hsiao YH (2014) Endometrial cancer incidence in breast cancer patients correlating with age and duration of tamoxifen use: a population based study. J Cancer 5(2):151-155. https://doi.org/10.7150/jca.8412

15. Segev Y, Iqbal J, Lubinski J, Gronwald J, Lynch HT, Moller P, Ghadirian P, Rosen B, Tung N, Kim-Sing C, Foulkes WD,
Neuhausen SL, Senter L, Singer CF, Karlan B, Ping S, Narod SA (2013) The incidence of endometrial cancer in women with BRCA1 and BRCA2 mutations: an international prospective cohort study. Gynecol Oncol 130(1):127-131. https://doi.org/10.1016/j. ygyno.2013.03.027

16. Swerdlow AJ, Jones ME (2005) Tamoxifen treatment for breast cancer and risk of endometrial cancer: a case-control study. J Natl Cancer Inst 97(5):375-384

17. Schaapveld M, Visser O, Louwman MJ, de Vries EG, Willemse PH, Otter R, van der Graaf WT, Coebergh JW, van Leeuwen FE (2008) Risk of new primary nonbreast cancers after breast cancer treatment: a Dutch population-based study. J Clin Oncol Off J Am Soc Clin Oncol 26(8):1239-1246. https://doi.org/10.1200/JCO. 2007.11.9081

18. Berkowitz Z, Rim SH, Peipins LA (2011) Characteristics and survival associated with ovarian cancer diagnosed as first cancer and ovarian cancer diagnosed subsequent to a previous cancer. Cancer Epidemiol 35(2):112-119. https://doi.org/10.1016/j.canep.2010.07.001

19. Welcsh PL, King MC (2001) BRCA1 and BRCA2 and the genetics of breast and ovarian cancer. Hum Mol Genet 10(7):705-713

20. Foulkes WD, Metcalfe K, Sun P, Hanna WM, Lynch HT, Ghadirian P, Tung N, Olopade OI, Weber BL, McLennan J, Olivotto IA, Begin LR, Narod SA (2004) Estrogen receptor status in BRCA1and BRCA2-related breast cancer: the influence of age, grade, and histological type. Clin Cancer Res 10(6):2029-2034

21. Jeon SY, Hwang KA, Choi KC (2016) Effect of steroid hormones, estrogen and progesterone, on epithelial mesenchymal transition in ovarian cancer development. J Steroid Biochem Mol Biol 158:1-8. https://doi.org/10.1016/j.jsbmb.2016.02.005

22. Ahmed SS, Thike AA, Zhang K, Lim JC, Tan PH (2017) Clinicopathological characteristics of oestrogen receptor negative, progesterone receptor positive breast cancers: re-evaluating subsets within this group. J Clin Pathol 70(4):320-326. https://doi.org/10. 1136/jclinpath-2016-203847 